UNCLASSIFIED: Distribution Statement A

Approved for public release

\title{
A six-component surrogate for emulating the physical and chemical characteristics of conventional and alternative jet fuels and their blends
}

Doohyun Kim ${ }^{\mathrm{a}}$, Jason Martz ${ }^{\mathrm{a}}$, Andrew Abdul-Nour ${ }^{\mathrm{b}}$, Xin Yu ${ }^{\mathrm{b}}$, Marcis Jansons ${ }^{\mathrm{b}}$, Angela Violi ${ }^{\mathrm{a}, \mathrm{c}}$

${ }^{\mathrm{a}}$ Department of Mechanical Engineering, University of Michigan, Ann Arbor, MI 48109-2125

${ }^{\mathrm{b}}$ Department of Mechanical Engineering, Wayne State University, Detroit, MI 48202

${ }^{\mathrm{c}}$ Departments of Chemical Engineering, Macromolecular Science and Engineering, Biophysics Program, Applied Physics University of Michigan, Ann Arbor, MI 48109-2125

Corresponding author: Angela Violi (ㅁioli@umich.edu)

2350 Hayward St.

2250 G.G. Brown

Ann Arbor, MI 48109-2125

(734) $615-6448$

\section{Disclaimer}

Reference herein to any specific commercial company, product, process, or service by trade name, trademark, manufacturer, or otherwise, does not necessarily constitute or imply its endorsement, recommendation, or favoring by the United States Government or the Department of Army (DoA). The opinions of the authors expressed herein do not necessarily state or reflect those of the United States Government or the DoA, and shall not be used for advertising or product endorsement purposes.

\section{UNCLASSIFIED}

(C) 2017. This manuscript version is made available under the Elsevier user license http://www.elsevier.com/open-access/userlicense/1.0/ 


\section{UNCLASSIFIED}

\section{Abstract}

Conventional and alternative jet fuels, such as petroleum-derived Jet-A, coal-derived IPK, and natural-gas-derived S-8, display significant chemical and physical fuel property differences that influence their ignition characteristics. The current work addresses the need for surrogate mixtures capable of emulating the various properties of these fuels and their select blends, which are often used within compression ignited engines for acceptable ignition behavior. A six-component surrogate palette is proposed with species that are readily available within recent kinetic mechanisms, including ndodecane, n-decane, iso-cetane, iso-octane, decalin, and toluene. The use of these species allows for a seamless compositional transition between the neat target jet fuels and their blends. The surrogate optimizer, which includes various correlations and models to estimate properties of model mixtures, is used to determine the surrogate composition that best matches target fuel properties. For an accurate ignition quality prediction during the optimization, a non-linear Derived Cetane Number regression equation is generated from Ignition Quality Tester experiments of 76 surrogate component mixtures. The newly formulated surrogates and their blends successfully capture the wide range of properties present within the target fuels, including temperature-dependent physical properties such as density, viscosity, specific heat, and volatility, along with experimental ignition delays obtained from a constant volume spray chamber. Kinetic modeling with a detailed mechanism showed that predicted ignition delay times are in good agreement with shock tube and rapid compression machine ignition delay experiments. A sensitivity analysis with variations in the composition of the Jet-A surrogate showed that its calculated ignition delay times are most sensitive to the composition of n-dodecane among the four Jet-A surrogate constituents over the range of temperatures and pressures examined.

Keywords: surrogate formulation, kinetic modeling, ignition delay, alternative fuels 


\section{UNCLASSIFIED}

\section{Introduction}

The detailed numerical simulation of the combustion of real fuels, which are composed of hundreds of species, remains beyond the realm of modern computing capabilities. To circumvent this problem, surrogate fuels can be defined with only a handful of components to emulate the combustion characteristics of the real fuel under study. Considering the wide range of jet fuels potentially used within the compression ignited engines of the U.S. military, a broad range of surrogate fuels are necessary for the detailed simulation of these engines. For example, the U.S. military operates with kerosene-based jet fuels for battlefield deployed aircraft and ground vehicles under the single fuel forward concept [1], along with synthetic jet fuels for energy security issues [2].

A number of different Synthetic Paraffinic Kerosenes (SPK) produced through the FischerTropsch process or by vegetable oil hydroprocessing have been tested as alternative jet fuels [2]. While SPKs are produced to have molecular size distributions similar to petroleum-derived jet fuels, discrepancies in the chemical and physical properties between the fuels can affect Diesel engine operation. SPKs are predominantly paraffinic in nature, which leads to significantly lower liquid density relative to petroleum-derived jet fuels. In turn, these liquid fuel density variations can influence injection related parameters such as injection velocity, which can impact the rate of fuel air mixing and the Diesel ignition process [3]. Another significant problem is the extreme variation in ignition quality between the different SPKs stemming from the lack of Cetane Number $(\mathrm{CN})$ specifications for jet fuels. In particular, the $\mathrm{CN}$ of SPKs under consideration by the U.S. military can range from 15 to 59 [4]. Such CN variation impacts Diesel engine ignition and combustion phasing, and leads to difficulties with cold starting and

fuel economy [5]. Due to such a significant difference in density and ignition quality, blends of conventional and alternative fuels are being used for military Diesel engines [5].

Using a handful of well-studied hydrocarbon molecules, fuel surrogates have been developed to mimic the combustion characteristics of complex real fuels, often with the intention of enabling 


\section{UNCLASSIFIED}

Computational Fluid Dynamic (CFD) simulation of the combustion process. A recent review paper by Dryer [6] provides a good summary of the progress in transportation fuel surrogate development. Over the last decade, there have been several efforts to formulate surrogates for petroleum-derived jet fuels [7-11], natural gas derived SPKs [12-15], a coal-derived SPK [16,17] and hydrotreated renewable jet fuels [18]. However, these surrogates did not consider emulating temperature-dependent physical properties that govern various spray phenomena in Diesel engines, such as liquid penetration length and evaporation, which makes their use in CFD simulations of direct injected Diesel engine problematic.

In this paper, we present new jet fuel surrogate formulations for conventional and synthetic jet fuels and their blends capable of emulating the physical and chemical properties of the target jet fuels. In order to capture the spray and combustion characteristics of these fuels within direct injected Diesel engines, the new formulation targets the following issues: 1) SPKs are highly paraffinic in content and although n-dodecane and iso-cetane were sufficient to represent the class of linear and branched alkanes in conventional Jet-A [19], additional surrogate components are required to match the various SPK target properties, 2) a recent study has identified liquid specific heat as an important fuel physical property that should be emulated [3], and finally 3) considering the wide CN range of SPKs and the importance of emulating ignition quality for Diesel applications, a new ignition quality prediction correlation is necessary for better accuracy compared with currently-used linear average methods.

In that regard, this study proposes a surrogate development methodology for different types of jet fuels with a wide range of properties using a six-component surrogate palette (n-dodecane, n-decane, iso-cetane, iso-octane, decalin, and toluene) and a surrogate optimizer that considers as targets the

Derived Cetane Number (DCN), Lower Heating Value (LHV), Hydrogen-Carbon ratio (H/C), Molecular Weight (MW), temperature-dependent density, viscosity, specific heat, along with the distillation characteristics of conventional and alternative jet fuels. A large set of DCN data is generated for the various mixtures of surrogate components, and a non-linear regression equation correlating surrogate 


\section{UNCLASSIFIED}

mixture composition to DCN is fit with this dataset for use in the surrogate optimizer. Kinetic modeling is used to assess the ability of the surrogates to emulate the ignition quality of the target jet fuels. A sensitivity study is conducted to estimate the effect of variations in the surrogate composition to the calculated ignition delay time. The importance of emulating temperature-dependent properties is also assessed through comparison with existing jet fuel surrogates that neglect such properties.

\section{Surrogate Formulation}

\subsection{Target Fuels and Properties}

Three fuels were examined in the current work, including petroleum-derived Jet-A POSF-4658, Iso-Paraffinic Kerosene (IPK) POSF-5642, which is a coal-derived SPK with a very low DCN of 31, and S-8 POSF-4734, which is a natural gas-derived SPK with a very high DCN of 60. 50/50 vol\% blends of Jet-A/IPK and Jet-A/S-8 were also considered. These specific batches of fuel were selected as the target fuels since a wide range of experimental data is currently available for these three fuels. Jet-A POSF-4658 is a composite blend of several different Jet-A batches, which is meant to represent a nominal petroleum-derived jet fuel. These three jet fuels have similar carbon number distributions [20], but their hydrocarbon class compositions and resulting fuel properties differ significantly. While petroleum-derived Jet-A is a complex mixture of n-alkanes, iso-alkanes, cyclic alkanes, and aromatic compounds [21], IPK and S-8 are composed entirely of normal and branched alkanes, except for IPK's small cyclic alkane fraction [20]. Despite their similar iso-alkane dominant compositions, IPK and S-8 have drastically different ignition quality (DCN of 31 vs 60), which stems from differing degrees of isoalkane branching in these fuels, with IPK having less-ignitable highly-branched iso-alkane species, and S-8 with mostly high ignition quality mono- or di-methyl alkanes [15,22].

The surrogate formulation for these target fuels focused on emulating the various properties affecting the ignition process of fuel spray. The target properties considered in the previous work 


\section{UNCLASSIFIED}

reported by our group [19] were maintained in the optimization, except for surface tension, which has been predicted to have only a marginal impact on liquid penetration length and ignition delay time [3]. The specific heat capacity of the liquid fuel was included as an additional target property, which is shown to affect liquid penetration length and ignition delay by influencing the amount of energy required for the evaporation of a given mass of fuel and, consequently, the local charge temperature [3]. The eight target properties of the target fuels, which are DCN, LHV, H/C ratio, MW, density, viscosity, specific heat, and distillation curve, are summarized in Table 1 [22-30]. The absence of aromatics in SPK composition can explain in part the differences in properties of these fuels compared to petroleum derived Jet-A, which contains up to $\sim 20 \%$ aromatics by volume [21]. For instance, due to the aromatics’ molecular structure with single or multiple benzene rings, these compounds generally have a lower H/C ratio and a higher liquid density than alkanes. These differences result in higher H/C and lower liquid density for SPKs relative to Jet-A. The current surrogate formulation effort seeks to capture the diverse range of compositional and property characteristics present within the target jet fuels.

\subsection{Six-Component Surrogate Palette}

Surrogates for the target fuels were formulated using molecules from a palette of six pure hydrocarbon components. By sharing a common palette, the oxidation of these surrogates as well as their blends can be simulated with a common chemical mechanism, which is an important benefit considering that the target fuels are often used as blends. The palette was built upon four pure molecules from the authors' previous work - n-dodecane, iso-cetane, decalin, and toluene [19]. Two additional alkanes (n-decane and iso-octane) were included to reflect the dominant alkane composition of IPK and S-8. Note that the decalin (CAS 91-17-8) used throughout this study is approximately a 60/40\% vol mixture of trans- and cis- isomers. Based on the wide range of $\mathrm{CN}$ among jet fuels [4], their hydrocarbon class compositions [20,21], and the actual hydrocarbon species found in the three target fuels by GC analysis $[22,25,28]$, the iso-alkane components in conventional and alternative jet fuels would ideally be 


\section{UNCLASSIFIED}

represented by highly-branched iso-alkane molecules in the $\mathrm{C} 10 \sim \mathrm{C} 14$ range, not with iso-octane $(\mathrm{C} 8,3$ methyl branches) and iso-cetane (C16, 7 methyl branches). However, chemical mechanisms for those iso-alkanes are not currently available. Thus, any progress in kinetic modeling of highly-branched isoalkanes between iso-octane and iso-cetane will benefit future jet fuel surrogate developments.

\subsection{Surrogate Optimizer with DCN Regression}

The surrogate optimizer reported in our previous work [19] was utilized to determine the surrogate composition that best matches the target fuel properties. The objective function of the optimization problem was defined as the weighted sum of the squared relative differences between the experimental data of the target fuel and the calculated/estimated values of the candidate surrogate mixtures as shown in the following expressions:

$$
\begin{gathered}
\text { ObjectiveFunction }=\sum_{i=1}^{N_{\text {target }}} w_{i} E_{i} \\
E_{i}=\frac{\sum_{j=1}^{N_{\text {data }, i}}\left(\frac{x_{i, j, c a l c}-x_{i, j, \exp }}{x_{i, j, \exp }}\right)^{2}}{N_{\text {data, } i}}
\end{gathered}
$$

where $i$ and $j$ are the indices for target properties and experimental data points, respectively, $x_{i, j, c a l c}$ is the calculated/estimated model mixture property value, $x_{i, j, \exp }$ is the experimentally measured value of the target fuel, $N_{\text {target }}$ is the number of target properties, $N_{\text {data }, i}$ is the number of experimental data points for the target property $i$, and $w_{i}$ is the weight for the target property $i$. The numbers of target data points $\left(N_{\text {data, } i}\right)$ for temperature-independent properties (DCN, LHV, H/C, MW) are one, while those for the temperature-dependent physical properties are summarized in

Table 2. The weights assigned to each target property within the objective function $\left(w_{i}\right)$ are reported in Table 1. DCN, density, specific heat, and distillation curve were given higher weights as compared to 


\section{UNCLASSIFIED}

the others, since these properties have been shown to be the most influential to the spray and combustion characteristics of compression ignition engines [3,31]. The different variability of each property between the components in the surrogate palette was also considered when determining the weights. The benefit of using different weights over equal weights is further discussed in the Supplementary Material.

An important contribution of this study is the improvement of the ignition quality estimation for the model mixture. In our previous work, the DCN of the model mixture was estimated by taking a linear average of the cetane numbers of pure components, based upon their respective liquid volume fraction. While this linear method has been widely used in other optimization-based surrogate development studies [13,32], it cannot capture non-linear blend effects influencing mixture DCN. In particular, it has been reported that the non-linear effect is significant when an n-alkane is blended with a low ignition quality iso-alkane; the increase in DCN resulting from n-alkane addition is much greater than the linear rate with the fraction of n-alkane addition [11,33]. To properly incorporate this nonlinearity into the optimization process, a non-linear regression equation correlating the mixture composition to DCN was implemented in the surrogate optimizer. For the formulation of the regression equation and the design of experiments, the simplex-lattice design of Scheffé $[33,34]$ was utilized with a 36-term polynomial to capture the linear and non-linear blending effects among six surrogate components:

$$
D C N=\sum_{i=1}^{6} \beta_{i} x_{i}+\sum_{i=1}^{5} \sum_{j=i+1}^{6} \beta_{i, j} x_{i} x_{j}+\sum_{i=1}^{5} \sum_{j=i+1}^{6} \delta_{i, j} x_{i} x_{j}\left(x_{i}-x_{j}\right)
$$

Equation 3

where $x_{i}$ is the volume fraction of the $i$ th surrogate component and $\beta_{i}, \beta_{i, j}$, and $\delta_{i, j}$ are the coefficients of the regression equation. The non-linear regression equation shown in Eq. 3 includes a linear average term $\left(\sum_{i=1}^{6} \beta_{i} x_{i}\right)$ along with second $\left(\sum_{i=1}^{5} \sum_{j=i+1}^{6} \beta_{i, j} x_{i} x_{j}\right)$ and third order $\left(\sum_{i=1}^{5} \sum_{j=i+1}^{6} \delta_{i, j} x_{i} x_{j}\left(x_{i}-x_{j}\right)\right)$ binary interaction terms. 


\section{UNCLASSIFIED}

This non-linear regression equation was fit to DCN measurements of 76 surrogate component mixtures covering a range of DCN from $13 \sim 74$ obtained from new Ignition Quality Tester (IQT) experiments. The full data matrix is provided in Table S1 of the Supplementary Material. Each DCN reported in this study is an average of 96 individual fuel injection and ignition events in total. The standard deviation of each DCN measurement estimated from the 96 ignition events is also reported. 57 out of the total 76 data points showed the standard deviations less than \pm 1 , with the highest being \pm 1.43 . Details on the experimental setup of IQT and its standard operating procedure are found in [35]. The data matrix started from the simplex-lattice design for second order mixtures (pure components and 50/50 binary mixtures) of the 6 components. The data matrix was then expanded to include 13 additional binary mixtures (n-dodecane/iso-octane or iso-cetane or toluene) and 46 mixtures (tertiary, 4-, 5-, and 6component mixtures) to improve the reliability of the regression model.

The non-linear regression model coefficients were determined with the method of least squares and are compared against the previous linear average method in Figure 1. The coefficients of the nonlinear regression equation are summarized in Table S2 of the Supplementary Material. The non-linear regression equation is well fit to the experimental data as indicated by the regression's $\mathrm{R}^{2}$ value of 0.998 , average relative error of $1.36 \%$, mean absolute error of $0.49 \mathrm{DCN}$ and maximum absolute error of 1.8 DCN. Figure 1 also clearly shows that the non-linear regression equation predictions are much more accurate than those from the linear average method, which has an average relative error of $10.4 \%$, a mean absolute error of 3.8 DCN and a maximum absolute error of 11.3 DCN. Given its accuracy, the non-linear regression equation was utilized to estimate the surrogate mixture DCN during the optimization process.

\subsection{Formulation Results and Discussions}

Table 3 summarizes the newly formulated surrogate compositions for Jet-A, IPK, and S-8. These surrogates are each 4-component mixtures that draw from several of the 6 hydrocarbon components 


\section{UNCLASSIFIED}

within the surrogate palette. In general, the surrogates successfully captured the compositional characteristics of the target fuels. The Jet-A surrogate includes a substantial amount of cyclo-alkane and aromatic compounds, similar to the targeted Jet-A POSF-4658. Also, the small cyclo-alkane content of IPK and purely paraffinic S-8 are well emulated by their respective surrogates.

Table 4 compares the temperature-independent target properties (DCN, LHV, H/C, and MW) of the surrogates and the target fuels. The three surrogates successfully emulated all of the targeted temperature-independent properties with a maximum deviation of $\sim 4.5 \%$ for MW. Most notably, the measured DCNs of the actual surrogate mixtures agreed well with the DCNs of the target fuels, with less than 1.2 DCN deviations for all three surrogates. The surrogate mixtures were also able to emulate the DCN of target Jet-A/SPK blends. As summarized in Table 5, the measured DCN of 50/50 vol\% blends of Jet-A surrogate/IPK surrogate and Jet-A surrogate/S-8 surrogate were 39.9 and 51.9, which agreed well with DCN's of 40.2 and 53.1 for Jet-A/IPK and Jet-A/S-8 target blends.

The current Jet-A surrogate shows a notably different composition when compared to the UM2 surrogate, a Jet-A POSF-4658 surrogate previously reported by our group [19] that includes identical surrogate components (n-dodecane/iso-cetane/decalin/toluene). The DCN of the actual UM2 mixture was measured at 40.6, which is significantly lower than the targeted DCN of 47.3. A reason for the large DCN deviations was the uncertainty in the pure component CN's. In particular, the decalin CN of 46.5 [36] used in our previous optimizer [19] originates from a measurement dating back to 1930s, which used a different experimental method (Cetene number measurement) [36] from the currently used ASTM D6890 method. Our measured decalin ( 60/40vol\% trans/cis) DCN was 32.9, which agrees better with other recent measurements $[37,38]$. Such a large error in the decalin $\mathrm{CN}$ resulted in a much lower measured DCN for UM2 relative to the predictions of the optimizer. For the current study, where a DCN regression equation generated from a single IQT machine was utilized, the device-to-device 


\section{UNCLASSIFIED}

uncertainty in the pure-component DCNs from the literature was eliminated, resulting in significantly better ignition quality emulation for the new Jet-A surrogate.

Figure 2 shows the predicted temperature-dependent liquid fuel density, viscosity, and specific heat of the surrogate compared with the measured property values of the target fuels. Target fuel density and viscosity were well matched by all three surrogates, with average relative deviations of less than $0.5 \%$ for density, and less than $2.7 \%$ for viscosity. For specific heat, the Jet-A and IPK surrogates displayed less than $3.0 \%$ average relative deviations from their target fuels, while the S-8 surrogate was within $5.6 \%$. These variations are well within the variability of the specific heat measurements of the targeted fuels, which displayed up to $20 \%$ measurement-to-measurement variance $[25,26]$. The densities of 50/50 vol\% surrogate blends were also well-matched to the target blends. At $288 \mathrm{~K}$ and $313 \mathrm{~K}$, where experimentally measured densities are available for the target blends [20], deviations in densities for surrogate blends were less than $1 \%$, as shown in Table 5.

Figure 3 shows the calculated distillation curves of the surrogate fuels and the values of the corresponding target fuels measured by the NIST's Advanced Distillation Curve metrology [22,29,30]. The surrogate optimizer calculates the distillation curve of a given mixture by solving the liquid-vapor equilibrium during the distillation process. More details of the distillation curve model implemented in the surrogate optimizer can be found in [19]. As seen in Figure 3 (a) and (c), the Jet-A and S-8 surrogates successfully predict the volatility of the target fuels as well as the overall shape of the distillation curve. This agreement indicates that not only the molecular size of the surrogate components is correct, but also that the vapor pressure distribution was appropriate for the Jet-A and S-8 surrogates. It is indeed important for simple surrogate mixtures to have well-distributed vapor pressures among the surrogate components to avoid critical curvature in the distillation curve [19]. On the other hand, Figure 3 (b) shows that the calculated distillation curve of the IPK surrogate only captures the mean volatility of the fuel and that the shape of the distillation curve is not as well emulated. As previously discussed, 


\section{UNCLASSIFIED}

iso-alkane content of IPK is nearly $90 \%$ by mass [20], which are mostly C10 C14 [22]. Since molecular weight and volatility are inversely correlated, the vapor pressure of iso-octane is too high while that of iso-cetane is too low to represent the volatility of the $\mathrm{C} 10 \sim \mathrm{C} 14$ iso-alkanes in the target IPK. Thus, emulating the distillation characteristics of these iso-alkanes with iso-octane (C8) and isocetane $(\mathrm{C} 16)$ in the surrogate palette is fundamentally a challenging task. In the future, a new highly branched iso-alkane surrogate component in the range of $\mathrm{C} 10 \sim \mathrm{C} 14$ is therefore required for an improved emulation of the IPK distillation curve. Also, the inclusion of surrogate components with molecular weight closer to that of the target fuel might improve the agreement for the distillation curve. For example, toluene $(92.1 \mathrm{~g} / \mathrm{mol})$ is too volatile as surrogate component for Jet-A $(157.5 \mathrm{~g} / \mathrm{mol})$, as indicated by the lower distillation temperatures of the Jet-A surrogate when the distilled volume is less than $20 \%$ (Figure 3 (a)). Thus, the emulation of the distillation characteristics can be augmented as the fidelity of kinetic mechanisms improves, making more hydrocarbons available as surrogate components.

Existing jet fuel surrogates are compared against those developed in the current work to highlight the contribution of the newly developed surrogates. As summarized in Table 6, surrogates in the literature having identical or similar target fuels to the current work are selected for comparison Surrogates A [11], B [8], and C [10] are for Jet-A, Surrogate D [17] is for IPK, and Surrogates E [14] and F [13] are for S-8. Surrogate properties were calculated using the surrogate optimizer with the pure hydrocarbon properties taken from the DIPPR property database [39]. Figure 4 compares the surrogate liquid densities against the experimentally measured densities of Jet-A, IPK, and S-8. It is shown that the surrogates developed in this work emulate the liquid density of the target fuels better than existing surrogates. The average relative deviations in densities of the newly developed Jet-A, IPK, and S-8 surrogates are $0.16 \%, 0.05 \%$, and $0.43 \%$; the smallest average relative deviations in densities among the existing surrogates are $5.5 \%, 2.4 \%$, and $2.9 \%$ for Jet-A, IPK, and S-8, respectively. Viscosities and distillation curves of the target fuels are more closely matched by the new surrogates as compared to the 


\section{UNCLASSIFIED}

previous formulations. Similar agreements between previous and new surrogates are observed for specific heat. Figures comparing liquid viscosity, specific heat, and distillation curve are included in Figure S1 of the Supplementary Material.

\section{Kinetic Modeling for the Surrogate Palette}

Gas phase ignition delays of the developed surrogates were calculated with CHEMKIN's constant volume homogeneous reactor model [40] and a detailed chemical mechanism from the Model Fuel Consortium (MFC) [41,42]. This mechanism includes all of the hydrocarbon species within the proposed six-component surrogate palette and is an updated version of the one used in [19], containing 4263 species and 18000 reactions. More details on the structure of the mechanism and the full list of species therein are found in [42]. Ignition delay calculations were compared to available measurements for the target Jet-A, IPK and S-8 fuels from shock tubes $[43,44]$ and a rapid compression machine [45]. The uncertainty in the ignition delay measurements is reported to be in the range of $\pm 10 \sim 25 \%$ [43-45].

Figure 5 shows the calculated and experimental ignition delays of Jet-A/air mixtures. For the 20 atm cases in Figure 5 (a), the Jet-A surrogate with the MFC mechanism successfully captures the overall ignition delay trend of the target POSF-4658 in all of the investigated temperature range. Calculated ignition delay times for the stoichiometric mixture agree very well with the experimental measurements in the high temperature and Negative Temperature Coefficient (NTC) regime $(\mathrm{T}>750 \mathrm{~K})$, while a longer ignition delay time is predicted in the low temperature regime $(\mathrm{T}<750 \mathrm{~K})$. For the slightly rich mixture $(\Phi=1.5)$, the agreement with the experimental data is also very good in the high temperature regime $(\mathrm{T}>950 \mathrm{~K})$, however shorter ignition delays are predicted within the NTC regime, and longer ignition delays are predicted at low temperatures. For the stoichiometric 40 atm case shown

in Figure 5 (b), good agreement is observed at high temperatures, but the calculated NTC ignition delay times are considerably shorter than the experiments, by up to a factor of 3. One of the primary reasons for the shorter ignition delays of the Jet-A surrogate at 40 atm in the NTC regime may be the MFC 


\section{UNCLASSIFIED}

mechanism's n-dodecane chemistry. Figure 6 (a) shows the calculated ignition delay of pure n-dodecane compared against shock tube measurements at elevated pressures $[46,47]$. The predicted NTC regime for n-dodecane at 40 atm is at higher temperatures with significantly shorter ignition delay times, while predicted ignition delay times are much closer to experimental measurements at $20 \mathrm{~atm}$. This clearly indicates that n-dodecane chemistry over-estimates the pressure effect on ignition delay time at high pressure, which explains in part the trend observed from the Jet-A surrogate simulations at 40 atm. Figure 6 (b) compares calculated ignition delay times of other Jet-A surrogate components (iso-cetane, decalin, toluene) against their respective shock tube measurements at high pressure [48-50]. However, the effect of these surrogate components' chemistry, in particular for iso-cetane and toluene, is uncertain, since ignition delay measurements from shock tubes do not exist for those two molecules in the temperature range where Jet-A NTC behavior is observed $(700 \mathrm{~K} \sim 950 \mathrm{~K})$.

To understand the relative effect of the Jet-A surrogate components and their oxidation chemistry on the calculated ignition delay time, the sensitivity of ignition delay to perturbations in surrogate composition was investigated as shown in Figure 7. The Jet-A surrogate composition was perturbed by adding $10 \%$ of each component's liquid volume fraction to the baseline surrogate mixture, which is similar to the method shown in [51]. The simulations were conducted at 20 atm and $\Phi=1$, where the agreement with experimental data was the closest as shown in Figure 5 (a). The first observation in Figure 7 is that for all composition perturbed cases, the largest ignition delay change occurs in the NTC regime around $\mathrm{T}=833 \mathrm{~K}(1000 / \mathrm{T}=1.2)$. Interestingly, this temperature and pressure condition is quite close to the nominal test conditions of recent DCN measurement devices such as the IQT (828 K at $21 \mathrm{~atm}$ ) [35] and Cetane Ignition Delay (873 K at $19.7 \mathrm{~atm}$ ) [52], which implies that the effect of the surrogate composition is most noticeable under conditions relevant to the DCN measurements. Figure 7 also shows that the calculated ignition delay times of the Jet-A surrogate are most sensitive to the composition of n-dodecane. Particularly in the NTC and low temperature regime (T 


\section{UNCLASSIFIED}

$<1000 \mathrm{~K})$, the relative change in ignition delay time of the $\mathrm{n}$-dodecane perturbation case $(-1 \% \sim-5 \%)$ is always greater than rest of the composition perturbation cases $(+1 \% \sim+2 \%)$. In the high temperature regime $(\mathrm{T}>1000 \mathrm{~K})$, the relative effects of surrogate components are similar and with smaller effect than within the NTC regime. Identical sensitivity study was also conducted at 40 atm and $\Phi=1$, which is the condition shown in Figure 5 (b), and the result showed the same trend to the 20 atm case (not shown). This sensitivity study suggests that the calculated ignition delay time of the Jet-A surrogate is most sensitive to the composition and oxidation chemistry of n-dodecane among the four Jet-A surrogate components, and its effect is most noticeable within the NTC regime.

Figure 8 compares the calculated ignition delays of the three surrogates against shock tube ignition delay measurements of three target jet fuels at 20 atm, the only pressure where shock tube ignition delay measurements [43] are currently available for IPK and S-8. Although the NTC regime for both IPK and S-8 is predicted to be within higher temperature regions, the calculated ignition delay times for both surrogates successfully capture the overall measurement trends; the quantitative ignition delay agreement however needs to be improved. In the high temperature regime above $1000 \mathrm{~K}$, the measured ignition delay times of the three fuels overlap - similar behaviors are also observed in the kinetic modeling results, where difference in calculated ignition delay times among the three fuels were always smaller than $0.2 \mathrm{~ms}$. In the low and NTC temperature regime where the ignition delay times are more distinguishable, the relative order of the calculated ignition delay times corresponds to the relative reactivity of the surrogates. As the measured DCN indicates, the reactivity of the S-8 surrogate is the highest (DCN of 61.1), followed by the Jet-A surrogate (DCN of 47.8), and finally the IPK surrogate (DCN of 31.9), which align well with the relative ignition delay times from the simulations.

\section{Summary and Conclusions}

In this paper, a six-component surrogate palette is proposed for formulating various petroleumderived and alternative SPK jet fuel surrogates. A surrogate optimizer, which uses models and 


\section{UNCLASSIFIED}

correlations to estimate the various chemical and physical properties of the HC mixtures, is utilized to determine the surrogate compositions that best fit the target fuel properties. A non-linear regression equation that correlates the surrogate mixture composition to $\mathrm{DCN}$ is fit to experimental ignition delays obtained from an IQT test apparatus and implemented within the surrogate optimizer for mixture DCN estimation. The newly formulated Jet-A, IPK, and S-8 surrogates successfully emulate the various chemical and physical properties known to affect liquid spray phenomena and chemical ignition behaviors during the Diesel combustion process. In addition, the DCNs of the newly developed surrogates are experimentally measured with the IQT and show good agreement with those of the target jet fuels and their blends, highlighting the effectiveness of the proposed six-component palette and the optimization-based methodology. Moreover, the 50/50 blends of the surrogates are also able to match DCNs and densities of the 50/50 blends of the target jet fuels. Ignition delay calculations for the surrogates are carried out using a detailed kinetic mechanism, which captures the ignition delay trends from experiments. A sensitivity study shows that the calculated ignition delay times of the Jet-A surrogate is influenced more by the composition and oxidation chemistry of n-dodecane than those of other Jet-A surrogate components. Physical properties of the new surrogates, in particular the distillation curves, indicate the need for the development of highly branched alkane chemistry in the C10 C14 range. Moreover, it highlights the need for additional fundamental ignition experiments and kinetic models within the intermediate/low temperature and high pressure regimes relevant to the Diesel engine ignition process.

\section{Acknowledgments}

Funding for this work was provided by the Automotive Research Center (ARC), A U.S. Army Center of Excellence in the modeling and simulation of ground vehicles at the University of Michigan, 


\section{UNCLASSIFIED}

with funding from government contract DoD-DoA W56HZV-04-2-0001 and DoD-DoA W56HZV-14-2-

0001 through the U.S. Army Tank Automotive Research, Development, and Engineering Center. 


\section{UNCLASSIFIED}

\section{References}

[1] U.S. Department of Defense. Directive 4140.25 - DoD Management Policy for Energy Commodities and Related Services. 2004.

[2] Blakey S, Rye L, Wilson CW. Aviation gas turbine alternative fuels: A review. Proc Combust Inst 2011;33:2863-85. doi:10.1016/j.proci.2010.09.011.

[3] Kim D, Martz J, Violi A. Effects of fuel physical properties on direct injection spray and ignition behavior. Fuel 2016;180:481-96. doi:10.1016/j.fuel.2016.03.085.

[4] Zhu Y, Li S, Davidson DF, Hanson RK. Ignition delay times of conventional and alternative fuels behind reflected shock waves. Proc Combust Inst 2015;35:241-8. doi:10.1016/j.proci.2014.05.034.

[5] Schihl P, Hoogterp-Decker L, Gingrich E. The Ignition Behavior of a Coal to Liquid FischerTropsch Jet Fuel in a Military Relevant Single Cylinder Diesel Engine. SAE Int J Fuels Lubr 2012;5:785-802. doi:10.4271/2012-01-1197.

[6] Dryer FL. Chemical kinetic and combustion characteristics of transportation fuels. Proc Combust Inst 2015;35:117-44. doi:10.1016/j.proci.2014.09.008.

[7] Violi A, Yan S, Eddings EG, Sarofim AF, Granata S, Faravelli T, et al. Experimental formulation and kinetic model for JP-8 surrogate mixtures. Combust Sci Technol 2002;174:399-417. doi:10.1080/00102200215080.

[8] Dagaut P, El Bakali A, Ristori A. The combustion of kerosene: Experimental results and kinetic modelling using 1- to 3-component surrogate model fuels. Fuel 2006;85:944-56. doi:10.1016/j.fuel.2005.10.008.

[9] Humer S, Frassoldati A, Granata S, Faravelli T, Ranzi E, Seiser R, et al. Experimental and kinetic modeling study of combustion of JP-8, its surrogates and reference components in laminar nonpremixed flows. Proc Combust Inst 2007;31:393-400. doi:10.1016/j.proci.2006.08.008.

[10] Honnet S, Seshadri K, Niemann U, Peters N. A surrogate fuel for kerosene. Proc Combust Inst 2009;32:485-92. doi:10.1016/j.proci.2008.06.218.

[11] Dooley S, Won SH, Heyne J, Farouk TI, Ju Y, Dryer FL, et al. The experimental evaluation of a methodology for surrogate fuel formulation to emulate gas phase combustion kinetic phenomena. Combust Flame 2012;159:1444-66. doi:10.1016/j.combustflame.2011.11.002.

[12] Mzé-Ahmed A, Hadj-Ali K, Diévart P, Dagaut P. Kinetics of Oxidation of a Synthetic Jet Fuel in a Jet-Stirred Reactor: Experimental and Modeling Study. Energy Fuels 2010;24:4904-11. doi:10.1021/ef100751q.

[13] Naik CV, Puduppakkam KV, Modak A, Meeks E, Wang YL, Feng Q, et al. Detailed chemical kinetic mechanism for surrogates of alternative jet fuels. Combust Flame 2011;158:434-45. doi:10.1016/j.combustflame.2010.09.016.

[14] Dooley S, Won SH, Jahangirian S, Ju Y, Dryer FL, Wang H, et al. The combustion kinetics of a synthetic paraffinic jet aviation fuel and a fundamentally formulated, experimentally validated surrogate fuel. Combust Flame 2012;159:3014-20. doi:10.1016/j.combustflame.2012.04.010.

[15] Huber ML, Smith BL, Ott LS, Bruno TJ. Surrogate Mixture Model for the Thermophysical Properties of Synthetic Aviation Fuel S-8: Explicit Application of the Advanced Distillation Curve. Energy Fuels 2008;22:1104-14. doi:10.1021/ef700562c.

[16] Huber ML, Lemmon EW, Diky V, Smith BL, Bruno TJ. Chemically Authentic Surrogate Mixture Model for the Thermophysical Properties of a Coal-Derived Liquid Fuel. Energy Fuels 2008;22:3249-57. doi:10.1021/ef800314b.

[17] Dooley S, Won SH, Haas FM, Santner JS, Ju Y, Dryer FL, et al. Development of Reduced Kinetic Models for Petroleum-Derived and Alternative Jet Fuels. AIAA 2014-3661 2014. 


\section{UNCLASSIFIED}

[18] Allen C, Valco D, Toulson E, Edwards T, Lee T. Ignition behavior and surrogate modeling of JP-8 and of camelina and tallow hydrotreated renewable jet fuels at low temperatures. Combust Flame 2013;160:232-9. doi:10.1016/j.combustflame.2012.10.008.

[19] Kim D, Martz J, Violi A. A surrogate for emulating the physical and chemical properties of conventional jet fuel. Combust Flame 2014;161:1489-98. doi:10.1016/j.combustflame.2013.12.015.

[20] Moses CA. Comparative Evaluation of Semi-Synthetic Jet Fuels. Coordinating Research Council; 2008.

[21] Shafer LM, Striebich RC, Gomach J, Edwards T. Chemical class composition of commercial jet fuels and other specialty kerosene fuels. AIAA 2006-7972 2006.

[22] Bruno TJ, Baibourine E, Lovestead TM. Comparison of Synthetic Isoparaffinic Kerosene Turbine Fuels with the Composition-Explicit Distillation Curve Method. Energy Fuels 2010;24:3049-59. doi:10.1021/ef100067q.

[23] Hui X, Kumar K, Sung C-J, Edwards T, Gardner D. Experimental studies on the combustion characteristics of alternative jet fuels. Fuel 2012;98:176-82. doi:10.1016/j.fuel.2012.03.040.

[24] Dryer FL, Jahangirian S, Dooley S, Won SH, Heyne J, Iyer VR, et al. Emulating the Combustion Behavior of Real Jet Aviation Fuels by Surrogate Mixtures of Hydrocarbon Fluid Blends: Implications for Science and Engineering. Energy Fuels 2014;28:3474-85. doi:10.1021/ef500284x.

[25] Bruno TJ, Huber ML, Laesecke A, Lemmon EW, McLinden M, Outcalt SL, et al. Thermodynamic, Transport, and Chemical Properties of "Reference" JP-8. National Institute of Standards and Technology; 2010.

[26] Bessee GB, Hutzler SA, Wilson GR. Analysis of Synthetic Aviation Fuels. Air Force Research Laboratory; 2011.

[27] Outcalt S, Laesecke A, Freund MB. Density and Speed of Sound Measurements of Jet A and S-8 Aviation Turbine Fuels $\uparrow$. Energy Fuels 2009;23:1626-33. doi:10.1021/ef800888q.

[28] Bruno TJ, Huber ML, Laesecke A, Lemmon EW, Outcalt SL, Perkins R, et al. The Properties of S8. NIST; 2006.

[29] Smith BL, Bruno TJ. Improvements in the Measurement of Distillation Curves. 4. Application to the Aviation Turbine Fuel Jet-A. Ind Eng Chem Res 2007;46:310-20. doi:10.1021/ie060938m.

[30] Bruno TJ, Smith BL. Improvements in the Measurement of Distillation Curves. 2. Application to Aerospace/Aviation Fuels RP-1 and S-8†. Ind Eng Chem Res 2006;45:4381-8. doi:10.1021/ie051394b.

[31] Bogin GE, DeFilippo A, Chen JY, Chin G, Luecke J, Ratcliff MA, et al. Numerical and Experimental Investigation of n-Heptane Autoignition in the Ignition Quality Tester (IQT). Energy Fuels 2011;25:5562-72. doi:10.1021/ef201079g.

[32] Huber ML, Lemmon EW, Bruno TJ. Surrogate Mixture Models for the Thermophysical Properties of Aviation Fuel Jet-A. Energy Fuels 2010;24:3565-71. doi:10.1021/ef100208c.

[33] Perez PL, Boehman AL. Experimental Investigation of the Autoignition Behavior of Surrogate Gasoline Fuels in a Constant-Volume Combustion Bomb Apparatus and Its Relevance to HCCI Combustion. Energy Fuels 2012;26:6106-17. doi:10.1021/ef300503b.

[34] Scheffé H. Experiments With Mixtures. J R Stat Soc Ser B Methodol 1958;20:344-60.

[35] ASTM D6890. ASTM International, West Conshohocken, PA; n.d.

[36] Murphy MJ, Taylor JD, McCormick RL. Compendium of Experimental Cetane Number Data. National Renewable Energy Laboratory; 2004.

[37] Santana RC, Do PT, Santikunaporn M, Alvarez WE, Taylor JD, Sughrue EL, et al. Evaluation of different reaction strategies for the improvement of cetane number in diesel fuels. Fuel 2006;85:643-56. doi:10.1016/j.fuel.2005.08.028. 


\section{UNCLASSIFIED}

[38] Heyne JS, Boehman AL, Kirby S. Autoignition studies of trans-and cis-decalin in an ignition quality tester (IQT) and the development of a high thermal stability unifuel/single battlefield fuel. Energy Fuels 2009;23:5879-5885.

[39] Design Institute for Physical Properties, Sponsored by AIChE. DIPPR Project 801 - Full Version. Design Institute for Physical Property Research/AIChE; 2012.

[40] CHEMKIN 10112. San Diego: Reaction Design; 2011.

[41] Model Fuels Consortium. Reaction Design; 2012.

[42] Puduppakkam KV, Wang C, Hodgson D, Naik C, Meeks E. Accurate and Dynamic Accounting of Fuel Composition in Flame Propagation During Engine Simulations. SAE 2016-01-0597 2016. doi:10.4271/2016-01-0597.

[43] Wang H, Oehlschlaeger MA. Autoignition studies of conventional and Fischer-Tropsch jet fuels. Fuel 2012;98:249-58. doi:10.1016/j.fuel.2012.03.041.

[44] Vasu SS, Davidson DF, Hanson RK. Jet fuel ignition delay times: Shock tube experiments over wide conditions and surrogate model predictions. Combust Flame 2008;152:125-43. doi:10.1016/j.combustflame.2007.06.019.

[45] Dooley S, Won SH, Chaos M, Heyne J, Ju Y, Dryer FL, et al. A jet fuel surrogate formulated by real fuel properties. Combust Flame 2010;157:2333-9. doi:10.1016/j.combustflame.2010.07.001.

[46] Shen H-PS, Steinberg J, Vanderover J, Oehlschlaeger MA. A Shock Tube Study of the Ignition of n-Heptane, n-Decane, n-Dodecane, and n-Tetradecane at Elevated Pressures. Energy Fuels 2009;23:2482-9. doi:10.1021/ef8011036.

[47] Vasu SS, Davidson DF, Hong Z, Vasudevan V, Hanson RK. n-Dodecane oxidation at highpressures: Measurements of ignition delay times and $\mathrm{OH}$ concentration time-histories. Proc Combust Inst 2009;32:173-80. doi:10.1016/j.proci.2008.05.006.

[48] Oehlschlaeger MA, Steinberg J, Westbrook CK, Pitz WJ. The autoignition of iso-cetane at high to moderate temperatures and elevated pressures: Shock tube experiments and kinetic modeling. Combust Flame 2009;156:2165-72. doi:10.1016/j.combustflame.2009.05.007.

[49] Zhu Y, Davidson DF, Hanson RK. Pyrolysis and oxidation of decalin at elevated pressures: A shock-tube study. Combust Flame 2014;161:371-83. doi:10.1016/j.combustflame.2013.09.005.

[50] Shen H-PS, Vanderover J, Oehlschlaeger MA. A shock tube study of the auto-ignition of toluene/air mixtures at high pressures. Proc Combust Inst 2009;32:165-72. doi:10.1016/j.proci.2008.05.004.

[51] Abianeh OS, Oehlschlaeger MA, Sung C-J. A surrogate mixture and kinetic mechanism for emulating the evaporation and autoignition characteristics of gasoline fuel. Combust Flame 2015;162:3773-84. doi:10.1016/j.combustflame.2015.07.015.

[52] ASTM D7668. ASTM International, West Conshohocken, PA. 


\section{UNCLASSIFIED}

\section{Figures}

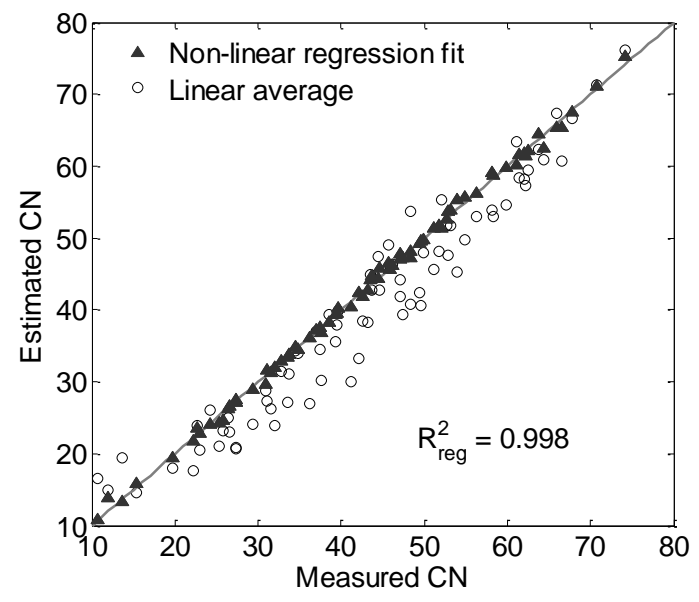

Figure 1. DCN estimations using the non-linear regression equation and the linear average method. $\mathrm{R}_{\text {reg }}^{2}$ is from the non-linear DCN regression equation. 


\section{UNCLASSIFIED}
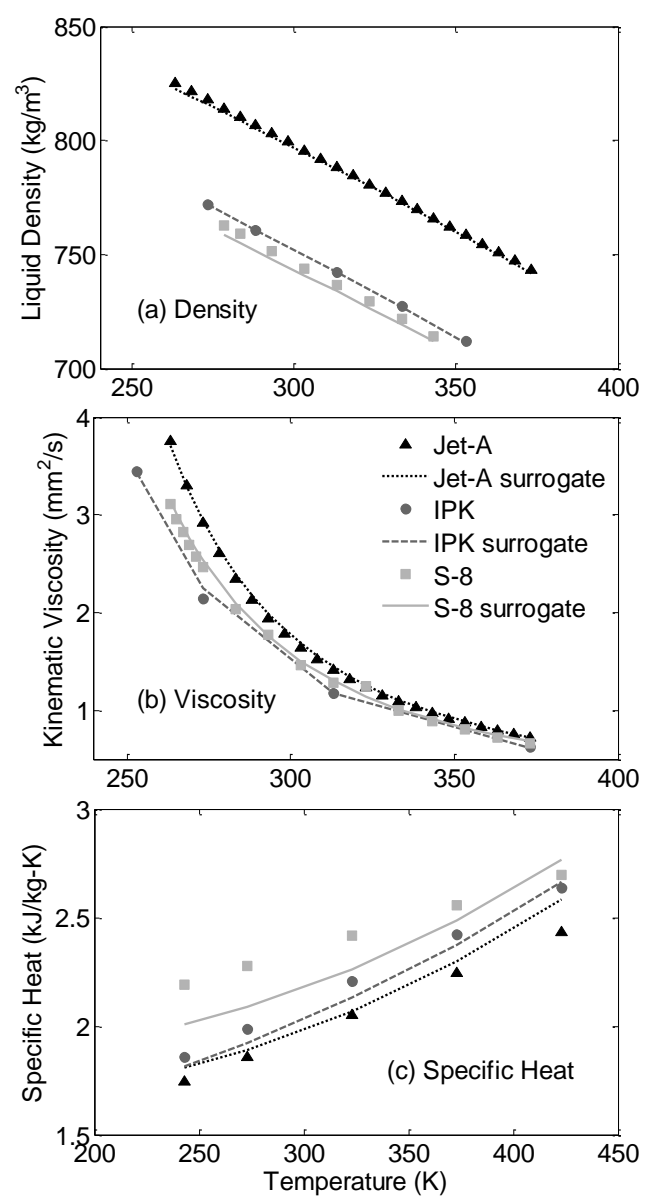

Figure 2. Calculated temperature-dependent (a) density, (b) viscosity, and (c) specific heat of the surrogates compared with the measured target fuel properties. 


\section{UNCLASSIFIED}
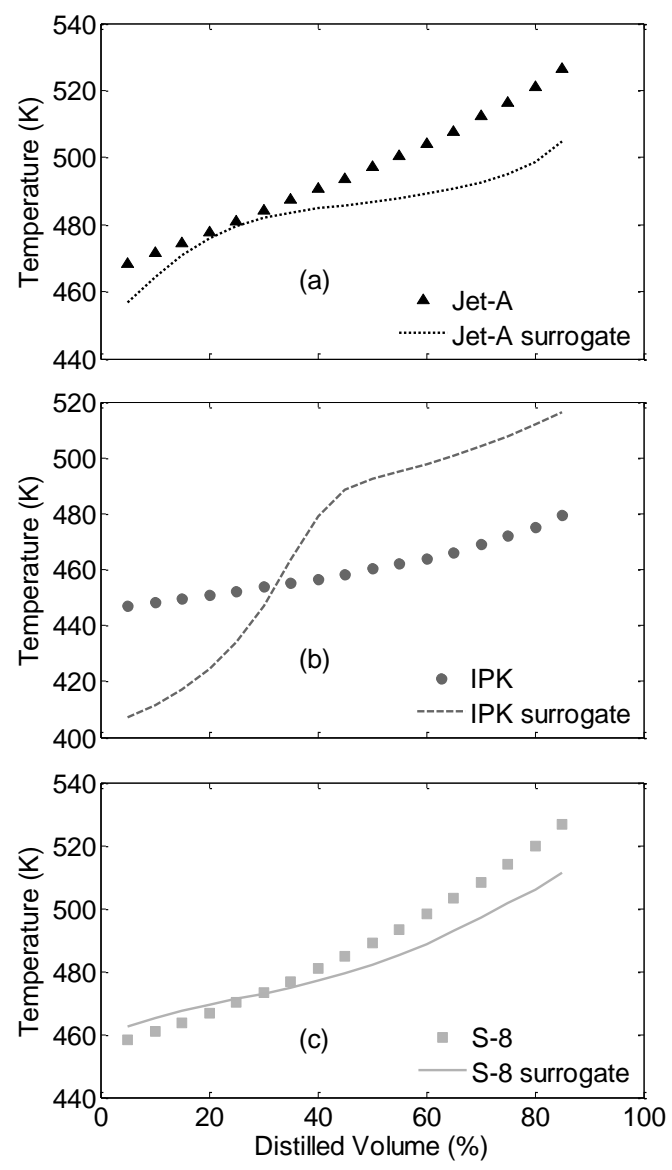

Figure 3. Calculated surrogate distillation curves for (a) Jet-A, (b) IPK, and (c) S-8 compared with the measured distillation curves of the respective target fuels.
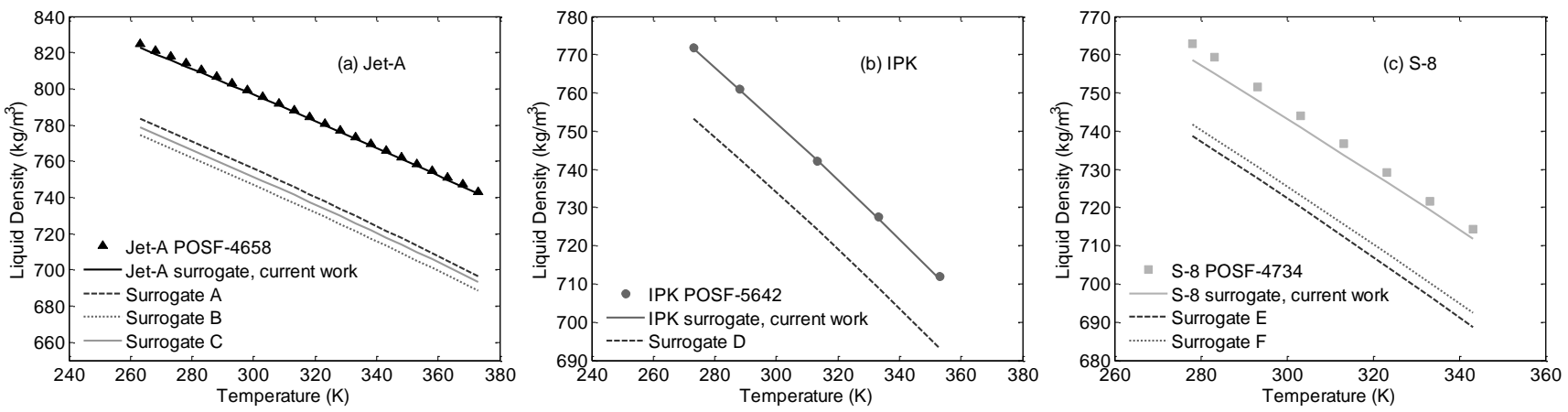

Figure 4. Comparisons of liquid densities for the newly developed surrogates and existing surrogates, (a)

Jet-A, (b) IPK, and (c) S-8. Densities of the surrogates are calculated using the surrogate optimizer, while the densities of the target fuels are from experimental measurements [25-27]. 


\section{UNCLASSIFIED}
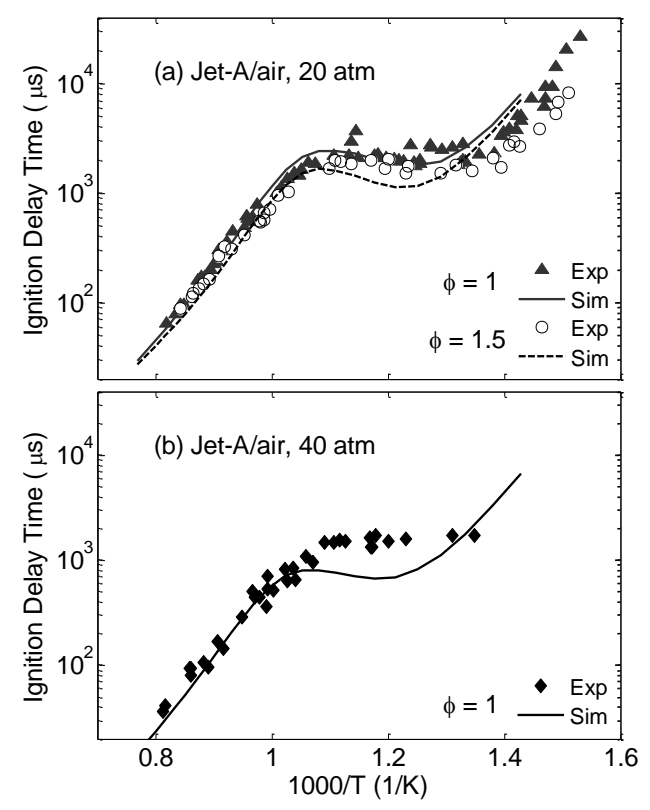

Figure 5. Comparisons of Jet-A/air mixture ignition delay measurements [43-45] with the calculated ignition delays using the Jet-A surrogates at (a) 20 atm and (b) $40 \mathrm{~atm}$.
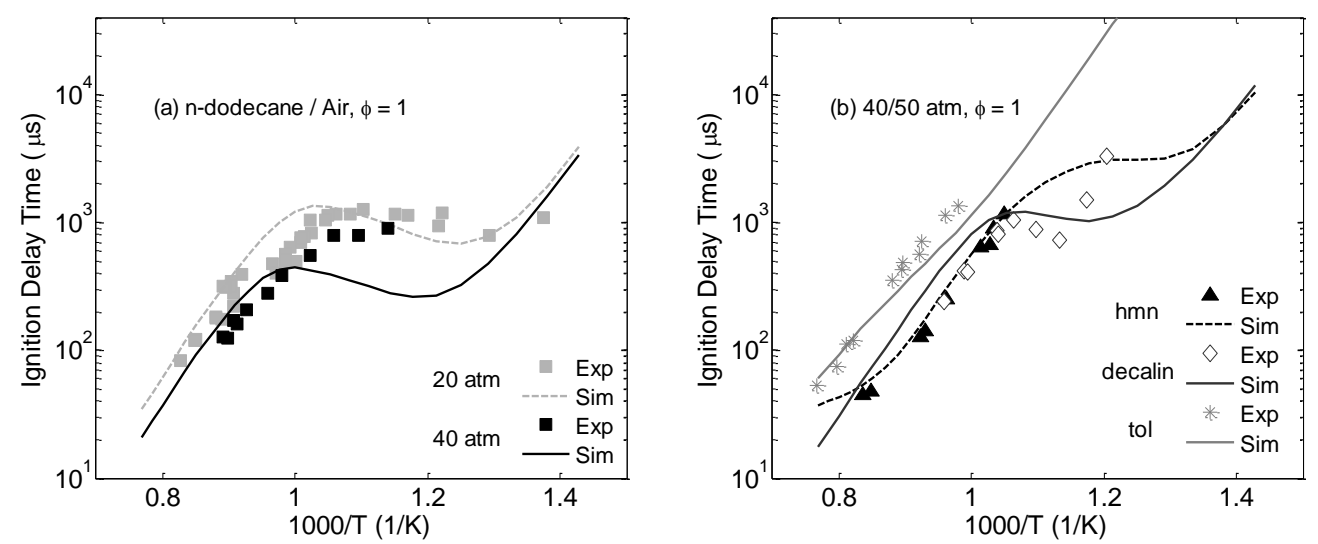

Figure 6. Comparison of stoichiometric fuel/air mixture ignition delay measurements for the Jet-A surrogate constituents [46-50] with calculated ignition delays from the MFC mechanism. (a) is for dodecane (dode) at $20 \mathrm{~atm}$ and $40 \mathrm{~atm},(\mathrm{~b})$ is for iso-cetane (hmn) at $40 \mathrm{~atm}$, and decalin and toluene (tol) at $50 \mathrm{~atm}$. 


\section{UNCLASSIFIED}
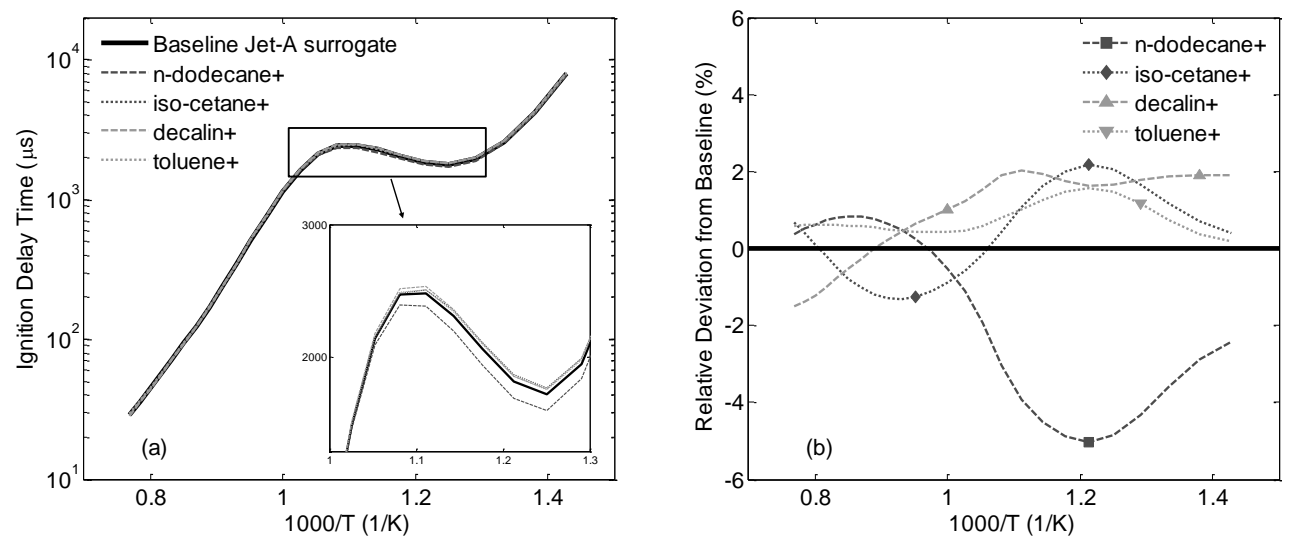

Figure 7. (a) Calculated ignition delay times and (b) the relative deviations from the baseline case for the Jet-A composition perturbation cases at 20 atm and equivalence ratio of 1 . The surrogate component with the + sign indicates a $10 \%$ increase in volume fraction.

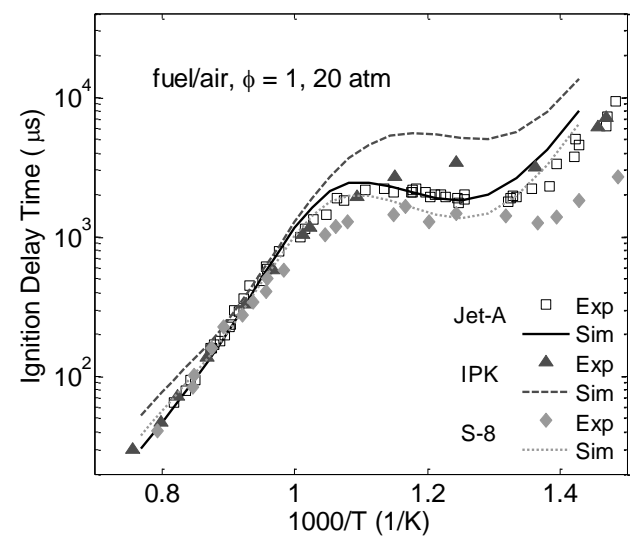

Figure 8. Comparison between the ignition delay of stoichiometric fuel/air mixture measurements at 20 atm and computed values for Jet-A, IPK, and S-8 surrogates. 


\section{UNCLASSIFIED}

\section{Tables}

Table 1. Measured target properties and their assigned weights for the optimization process.

\begin{tabular}{|c|c|c|c|c|}
\hline Target properties & Jet-A POSF-4658 & IPK POSF-5642 & S-8 POSF-4734 & Weight \\
\hline $\mathrm{DCN}(\mathrm{IQT})^{\mathrm{a}}$ & $47.3 \pm 0.67$ & $30.7 \pm 0.32$ & $60.36 \pm 0.99$ & 10 \\
\hline LHV (MJ/kg) & $42.8[23]$ & $44.0[23]$ & $44.1[23]$ & 1 \\
\hline $\mathrm{H} / \mathrm{C}$ ratio & $1.957[23]$ & $2.119[23]$ & $2.152[23]$ & 1 \\
\hline MW & $157.5[24]$ & $156[23]$ & $168[23]$ & 1 \\
\hline Density & {$[25]$} & [26] & {$[27]$} & 25 \\
\hline Viscosity & [25] & [26] & {$[28]$} & 1 \\
\hline Specific heat & [26] & [26] & {$[25]$} & 5 \\
\hline Distillation curve & [29] & [22] & {$[30]$} & 5 \\
\hline
\end{tabular}

${ }^{\mathrm{a}}$ (average) \pm (standard deviation) from 96 individual injection and ignition events

Table 2. Number of data points for each temperature-dependent physical properties used in the surrogate optimization.

\begin{tabular}{llcc}
\hline & \multicolumn{2}{l}{ The number of data points } \\
& Jet-A & IPK & S-8 \\
& 23 & 5 & 8 \\
\hline Density & 23 & 4 & 16 \\
Viscosity & 5 & 5 & 5 \\
Specific Heat & 17 & 17 & 17 \\
Distillation Curve & 17 &
\end{tabular}




\section{UNCLASSIFIED}

Table 3. Compositions of the optimized surrogate fuels in volume fractions.

\begin{tabular}{llll}
\hline & Jet-A Surrogate & IPK Surrogate & S-8 Surrogate \\
\hline n-dodecane & 0.4706 & 0.1416 & 0.3073 \\
n-decane & 0 & 0 & 0.4234 \\
iso-cetane & 0.1669 & 0.3141 & 0.2309 \\
iso-octane & 0 & 0.4016 & 0.0384 \\
decalin & 0.2419 & 0.1427 & 0 \\
toluene & 0.1206 & 0 & 0 \\
\hline
\end{tabular}

Table 4. Temperature-independent properties of the target fuels and their surrogates.

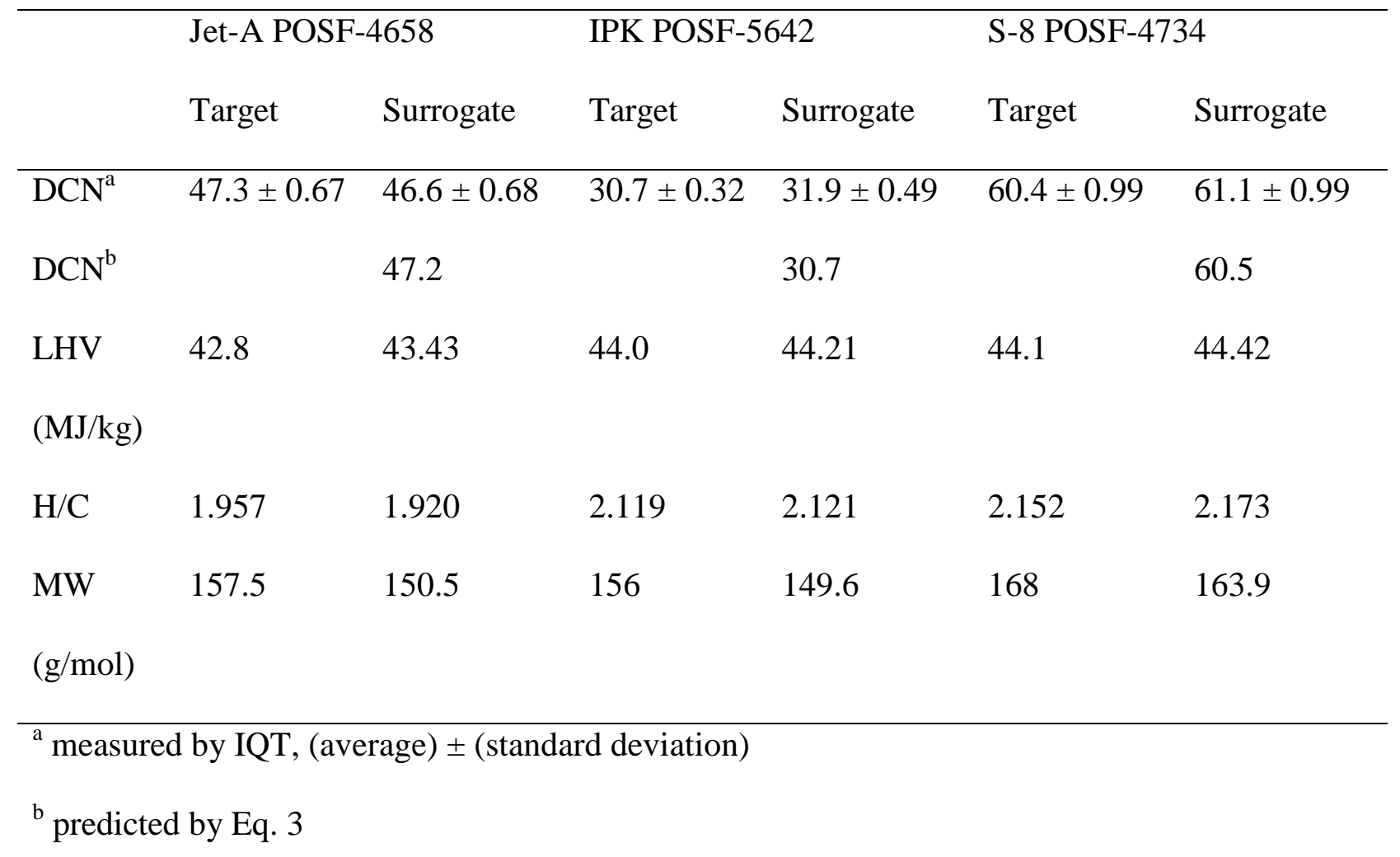




\section{UNCLASSIFIED}

Table 5. DCN and density of the target fuels and their surrogate blends.

\begin{tabular}{lllll}
\hline & Jet-A / IPK 50/50 vol\% & \multicolumn{2}{l}{ Jet-A / S-8 50/50 vol\% } \\
& Target blend & Surrogate blend & Target blend & Surrogate blend \\
& $40.2 \pm 0.57$ & $39.9 \pm 0.51$ & $53.1 \pm 0.72$ & $51.9 \pm 0.76$ \\
\hline DCN $^{\mathrm{a}}$ & 784 & 779 & 781 & 773 \\
Density @ 288K $\left(\mathrm{kg} / \mathrm{m}^{3}\right)$ & 766 & 761 & 761 & 756 \\
Density @ 313K $\left(\mathrm{kg} / \mathrm{m}^{3}\right)$ & 766 & & & \\
\hline
\end{tabular}

${ }^{\mathrm{a}}$ measured by IQT, (average) \pm (standard deviation)

Table 6. List of current jet fuel surrogates present in the literature for physical property comparisons.

\begin{tabular}{|c|c|c|c|}
\hline Surrogate & Target Fuel & Surrogate composition & Ref \\
\hline Surrogate A & $\begin{array}{l}\text { Jet-A } \\
\text { POSF-4658 }\end{array}$ & $\begin{array}{l}\text { n-dodecane/iso-octane/1,3,5-trimethylbenzene/n-propylbenzene } \\
=0.4041 / 0.2948 / 0.0728 / 0.2283, \text { mole fraction }\end{array}$ & [11] \\
\hline Surrogate B & Jet-A-1 & $\begin{array}{l}\text { n-decane/n-propylbenzene/n-propylcyclohexane } \\
=0.74 / 0.14 / 0.12 \text {, mole fraction }\end{array}$ & [8] \\
\hline Surrogate C & JP-8 & $\begin{array}{l}\text { n-decane/1,2,4-trimethylbenzene } \\
=0.8 / 0.2 \text {, mass fraction }\end{array}$ & [10] \\
\hline Surrogate D & $\begin{array}{l}\text { IPK } \\
\text { POSF-5642 }\end{array}$ & $\begin{array}{l}\text { n-dodecane/n-hexadecane/iso-octane/iso-cetane } \\
=0.057 / 0.035 / 0.607 / 0.301, \text { mole fraction }\end{array}$ & [17] \\
\hline Surrogate E & $\begin{array}{l}\text { S-8 } \\
\text { POSF-4734 }\end{array}$ & $\begin{array}{l}\text { n-dodecane/iso-octane } \\
=0.519 / 0.481, \text { mole fraction }\end{array}$ & [14] \\
\hline Surrogate F & S-8 & $\begin{array}{l}\text { n-dodecane/n-decane/iso-octane } \\
=0.43 / 0.25 / 0.32, \text { mole fraction }\end{array}$ & [13] \\
\hline
\end{tabular}

